\title{
Escherichia coli ve Klebsiella pneumoniae Suşlarında GSBL Üretiminin Saptanmasinda VITEK- 2 Otomatize Sistemi ile Çift Disk Sinerji Testinin Karşlaștırılmasi ${ }^{\S}$
}

\author{
Serpil GENÇ, Devrim DÜNDAR \\ Kocaeli Üniversitesi Tıp Fakültesi, Tıbbi Mikrobiyoloji Anabilim Dalı
}

\section{ÖZET}

Amaç: CLSI ve EUCAST'ın yenilenen dökümanlarında genişlemiş spektrumlu beta-laktamaz (GSBL) varlığının araştırılması rutin olarak önerilmese de, hâlen enfeksiyon kontrolü amacı ile ve epidemiyolojik çalışmalarda araşttrılması önerilmektedir. Bu çalışmada, GSBL varlığını saptamada VITEK 2 (bioMérieux, Fransa) tam otomatize sistemi ile Çift Disk Sinerji (ÇDS) testi arasinda fark olup olmadığının araştırılması amaçlanmıştır.

Gereç ve Yöntem: Çeşitli klinik örneklerden 2014 yılı içerisinde enfeksiyon etkeni olarak izole edilen 95 Escherichia coli ve 61 Klebsiella pneumoniae suşu çalışmaya alınmıştır. Daha önce VITEK 2 sistemi ile duyarlıllk testleri yapılmış olan suşlar stoktan çıkarıldıktan sonra iki kez pasajlanmış ve ÇDS testi uygulanmıştır. VITEK 2 ile GSBL pozitif bulunan altı K. pneumoniae ve iki E. coli suşu ÇDS testinde tüm antibiyotiklere dirençli bulunduğundan, de ğerlendirmeye alınmamıştır.

Bulgular: VITEK 2'nin GSBL negatif sonuç verdiği bir E. coli ve üç K. pneumoniae suşu ÇDS testi ile GSBL pozitif; VITEK 2'nin GSBL pozitif sonuç verdiği on iki E. coli ve dört $K$. pneumoniae suşu ise ÇS testi ile negatif bulunmuştur. ÇDS testi altın standart olarak kabul edildiğinde, VITEK 2'nin duyarlılığ $\% 93.3$, özgüllü̈̆̈̈̈ \%81.8, yanlıs pozitiflik oranı \%18.1, yanlış negatiflik oranı \%6.6 ve doğ ruluk oranı \%86.4 olarak saptanmıştır.

Sonuç: Çalıșmamızda elde ettiğimiz verilere göre, VITEK 2 otomatize sistemi ile GSBL saptanmasinda yalancı negatif ve yalancı pozitif sonuçlar alınabilmekle birlikte, duyarlılık ve özgüllü̈̆̈̈nün yüksek olduğu görülmektedir. Ancak bunun referans yöntem olmadığ sonuçlarda ikinci bir test ile GSBL varlı̆̆l/yokluğu do ğrulanmalıdır.

\section{SUMMARY}

Comparison of VITEK-2 Automated System and Double Disk Synergy Test for Detection of ESBL Production of Escherichia coli and Klebsiella pneumoniae Strains

Objective: Although routine investigation of the presence of the ESBL is not recommended in the new CLSI and EUCAST guidelines, it is recommended to test ESBL as a part of infection control and for epidemiological purposes. The aim of this study was to compare Disk Approximation Method (DAM) and VITEK 2 (bioMérieux, France) fully automated test system fort he determination of ESBL in Escherichia coli and Klebsiella pneumoniae strains.

Materials and Methods: A total of 95 E.coli and 61 $K$. pneumoniae strains isolated from various clinical specimens in 2014 were included in the study. The antibiotic susceptibility testing of the isolates were previously performed by VITEK 2 system. DAM was performed on the strains which were grown from the stock series. Six $K$. pneumoniae and two E. coli strains which were ESBL (+) with VITEK 2, were found to be resistant to all antibiotics with DAM and these isolates were not assessed.

Results: One E. coli and three K. pneumoniae strains were found ESBL negative with VITEK-2, but were positive with $D A M$, twelve E. coli and four K. pneumoniae strains were found ESBL positive with VITEK-2, but were negative with DAM. Sensitivity, specificity, false positive, false negative and accuracy rates of VITEK-2 were 93.3\%, $81.8 \%$, $18.1 \%, 6.6 \%$ and $86.4 \%$ respectively when DAM was accepted as the gold standard test.

Conclusion: According to the data obtained in this study it was concluded that although VITEK 2 automated system yielded false negative and false positive results, it revealed high sensitivity and specificity for ESBL detection. However, since automated systems are not considered as reference methods, discordant ESBL results should be verified with a second test.

Key words: ESBL, disk approximation method, VITEK-2

\footnotetext{
Alındığı tarih: 17.08.2015
}

Kabul tarihi: 16.11.2015

Yazışma adresleri: Serpil Genç, Kocaeli Üniversitesi Tıp Fakültesi, Tıbbi Mikrobiyoloji Anabilim Dalı, Kat:4, Kocaeli

e-posta: metin.serpil@yahoo.com

${ }^{\S}$ Bu araştırma 12-16 Kasım 2014 tarihleri arasında Belek, Antalya'da düzenlenen XXXVI. Türk Mikrobiyoloji Kongresi'nde poster olarak sunulmuştur. 


\section{GíRiş}

Genişlemiş spektrumlu beta-laktamaz (GSBL)'lar; penisilinleri, 1.-4. kuşak sefalosporinleri ve monobaktamları hidrolize eden enzimlerdir ve bu antibiyotiklere direnç gelişimine neden olurlar. Klavulanik asit, tazobaktam, sulbaktam gibi beta-laktamaz inhibitörleri ile inhibe olurlar. Sefamisinler ve karbapenemler bu enzimlerden etkilenmez. GSBL'ler ilk kez 1983 yilında tanımlanmıştır ve dünya genelinde yaygın olarak görülmektedir ${ }^{(1)}$. GSBL üretimi genellikle Escherichia coli, Klebsiella pneumoniae ve Proteus mirabilis başta olmak üzere enterik bakterilerde görülmekle birlikte, Pseudomonas aeruginosa ve Acinetobacter baumannii gibi non fermentatif bakterilerde de gözlenmektedir $^{(2,6)}$. GSBL enzimleri kromozomal ve bakteriler arasında aktarılabilen plazmidler üzerinde kodlanmaktadir $^{(9)}$. GSBL'lerin TEM, SHV, CTX-M, OXA, PER, GES gibi çeşitli tipleri bulunmaktadır ve günümüzde 250'den fazla GSBL enzimi tanımlanmıştır ${ }^{(10)}$. GSBL üreten bakteriler çoğul dirençli olduğundan, neden oldukları enfeksiyonlarda kullanılabilecek antibiyotikler kısıtlanmakta ve tedavileri zorlaşmaktadır. Hastaların hastanede yatış süresi uzamakta ve beraberinde hastane enfeksiyonu gelişimine zemin hazırlamaktadır.

\section{CLSI (Clinical and Laboratory Standards} Institute) ve EUCAST (European Committee on Antimicrobial Susceptibility Testing)'ın yenilenen dökümanlarında GSBL varlığının araştırılması rutin olarak önerilmese de, hâlen enfeksiyon kontrolü amacı ile ve epidemiyolojik çalışmalarda araştırılması önerilmektedir ${ }^{(1,2)}$. GSBL saptanması amaciyla tarama ve doğrulama testleri önerilmektedir. Tarama testi olarak sefotaksim, seftriakson, seftazidim, sefpodoksim ile disk difüzyon testiyle inhibisyon çapı veya agar/ broth dilüsyon yöntemi ile minimum inhibitör konsantrasyon (MİK) saptanır. Saptanan zon çapları, test edilen antibiyotikler için uluslararası kaynaklarda belirlenen sınır değerlerinden küçük veya MIK değerleri sınır değerlerinden büyük çıkarsa doğrulama testi yapılmalıdır. Doğrulama testleri ise, kombinasyon disk testi (KDT), çift disk sinerji testi (ÇDS), GSBL gradiyent strip testi ve sıv1 mikrodilüsyon testi gibi fenotipik testler ile PCR gibi genotipik testlerdir ${ }^{(1,2)}$. Çeşitli ticari kitler ve otomatize sistemler de GSBL varlığını saptayabilmektedir ${ }^{(7)}$.

ÇDS testi ucuz, uygulama ve değerlendirmesinin kolay olması nedeniyle GSBL saptanması için laboratuvarlarda sık kullanılan yöntemlerden biridir $^{(7,8)}$.

Çalışmamızda, GSBL varlığını saptamada VITEK 2 (bioMérieux, Fransa) tam otomatize sistemi ile ÇDS testinin karşılaştırılması amaçlanmıştır.

\section{GEREÇ ve YÖNTEM}

Çeşitli klinik örneklerden 2014 yılı içerisinde enfeksiyon etkeni olarak izole edilen 95 E. coli ve $61 K$. pneumoniae suşu çalışmaya alınmıştır. Daha önce VITEK 2 (bioMérieux, Fransa) sistemi ile duyarlılık testleri yapılmış ve $-80^{\circ} \mathrm{C}$ 'de saklanmakta olan suşlar stoktan çıkarıldıktan sonra iki kez pasajlanmış ve ÇDS testi uygulanmıştır. Bunun için taze bakteri kültüründeki kolonilerden 0.5 McFarland bulanıklığına eşit olacak şekilde bakteri süspansiyonu hazırlanıp, Mueller Hinton Agar plağına inoküle edilmiştir. Üç antibiyotik diski [aztreonam $(30 \mu \mathrm{g})$, seftriakson $(30 \mu \mathrm{g})$, seftazidim $(30 \mu \mathrm{g})]$ amoksisilinklavulanik asit $(20 / 10 \mu \mathrm{g})$ diskinin merkezinden $20 \mathrm{~mm}$ uzağa konularak, $35^{\circ} \mathrm{C}$ ' de 18 saat inkübe edilmiştir ${ }^{(1,15)}$. VITEK 2 ve ÇDS testi arasında uyumsuzluk bulunan 13 E. coli ve 7 K. pneumoniae suşu için ÇDS testi $2 \mathrm{kez}$ yinelenmiş ve aynı sonuçlar alınmıştır.

VITEK 2 ile GSBL pozitif bulunan alt K. pneumoniae ve iki E. coli suşu ÇDS 
testinde tüm antibiyotiklere dirençli bulunduğundan değerlendirmeye alınmamıştır.

Antibiyotik disklerine ait inhibisyon zonlarının amoksisilin-klavulanik asit diskine doğru genişleme göstermesi veya diskler arasındaki bölgede inhibisyon alanı gözlenmesi GSBL üretimi olarak değerlendirilmiştir ${ }^{(1)}$.

Çalışmada kullanılan tüm antibiyotik diskleri Oxoid (Oxoid Ltd, Basingstoke, Birleşik Krallık) firmasından sağlanmıştır. GSBL varlığının değerlendirilmesinde pozitif kontrol suşu olarak $K$. pneumoniae ATCC 700603, negatif kontrol suşu olarak E. coli ATCC 25922 kullanılmıştır ${ }^{(1)}$.

\section{BULGULAR}

Çalışılan suşların 90'ı idrar, 26'sı deri-yumuşak doku, 21'i solunum sistemi, 13'ü steril vücut sıvısı, 6'sı kan-kateter örneklerinden izole edilmiştir (Tablo 1).

VITEK 2 ve ÇDS testlerine göre GSBL sonuçları Tablo 2'de görülmektedir. VITEK 2'nin GSBL negatif sonuç verdiği bir $E$. coli ve üç $K$. pneumoniae suşu ÇDS testi ile GSBL pozitif, VITEK 2'nin GSBL pozitif sonuç verdiği on iki E. coli ve dört $K$. pneumoniae suşu ise ÇDS testi ile negatif bulunmuştur (Tablo 2).

ÇDS testi referans alınarak yapılan değerlendirmede, VITEK 2'nin duyarlılığg \%93.3, özgüllüğü \%81.8, yanlış pozitiflik oran1 $\% 18.1$, yanlış negatiflik oran1 \%6.6 ve doğruluk oranı $\% 86.4$ olarak saptanmıştır.
Tablo 2. VITEK 2 ve ÇDS testlerine göre GSBL sonuçları (suş sayıları).

\begin{tabular}{rcccc}
\hline & \multicolumn{3}{c}{ Çift Disk Sinerji testi } \\
\cline { 2 - 4 } & GSBL (+) & GSBL (-) & Toplam \\
\hline VITEK-2 & GSBL (+) & 56 & 16 & 72 \\
GSBL (-) & 4 & 72 & 76 \\
\cline { 2 - 4 } & Toplam & 60 & 88 & 148 \\
\hline
\end{tabular}

\section{TARTIŞMA}

Sefalosporinler 1980'lerin başından itibaren kullanıma girmiştir ve yaygın olarak kullanılmas1 ile de mikroorganizmalardaki GSBL enzimi üretimi son yıllarda artış göstermektedir. GSBL varlığında tüm penisilinlere, sefalosporinlere (sefamisinler hariç) ve monobaktamlara karş1 direnç gelişmektedir. Bu durum tedavi başarısızlığına yol açmaktadır ${ }^{(12)}$. Rutin hasta hizmeti veren laboratuvarların çoğunda, iş yükünün fazla olması nedeniyle GSBL varlığı otomatize sistemler ile araştırılmaktadır. Eski CLSI ve EUCAST kaynaklarında, özellikle K. pneumoniae, E. coli ve P. mirabilis için GSBL tarama ve doğrulama testlerinin yapılması gerektiği bildirilmekte iken ${ }^{(4,5)}$, yenilenen dökümanlarda sefalosporinler ve aztreonamın sınır değerleri revize edildiğinden, GSBL taranması rutin olarak önerilmemektedir. Ancak, enzim varlığının bilinmesinin enfeksiyon kontrolü açısından yararlı olacağı vurgulanmaktadır ${ }^{(2,3)}$.

Dünyanın pek çok bölgesinde GSBL üretimini saptayan yöntemler ile ilgili çeşitli çalışmalar yapılmıştır. Çeşitli otomatize sistemler ve ÇDS testi kullanılarak 150 enterik bakteri ile yapılmış karşılaştırmalı bir çalışmada, moleküler metotlar referans olarak alındığında, VITEK 2 (bioMérieux, Fransa), Phoenix Automated Microbiology

Tablo 1. İzolatların örnek türüne göre dağılımı.

\begin{tabular}{lcrrrr}
\hline & Deri ve Yumuşak Doku & Solunum & Kan-Kateter & Steril Vücut Sıvısı & İdrar \\
\hline K. pneumoniae & 11 & 15 & 4 & 2 \\
E. coli & 15 & 6 & 2 & 11 \\
\hline
\end{tabular}


System (BD Diagnostic Systems, Sparks, MD, ABD), MicroScan WalkAway-96 System (Dade Behring, Inc., West Sacramento, CA, ABD), ÇDS testi ve E-test yöntemlerinin GSBL saptanmasinda duyarlılıkları sirasiyla \%84.5, \%100, \%98.6, \%94.4, \%98.6, özgüllükleri ise \%93.9, $\% 51.5, \% 51.5, \% 97, \% 72.7$ olarak bulunmuş ve ÇDS testinin rutin laboratuvarlar için daha uygun bir yöntem olabileceği sonucuna varılmıştır(11).

Daha önce moleküler yöntemler ile çalışılmış olan 94 GSBL pozitif ve 71 GSBL negatif enterik bakteri ile yapılan bir çalışmada, VITEK 2'nin duyarlılı̆̆g $\% 90.5$, özgüllü̆̆ü $\% 100$, ÇDS testinin duyarlılığ1 \%100, özgüllüğü \%97.4, kombine disk testinin duyarlılığ1 \%90.5, özgüllüğü \%100 olarak saptanmıştır ${ }^{(13)}$.

GSBL pozitifliği kombinasyon disk difüzyon testi ile belirlenmiş olan 117 enterik bakteri ile yapılan bir çalışmada, VITEK-2 ile suşların \%91'i, ÇDS testi ile ise \%97'si GSBL pozitif olarak saptanmış ve VITEK 2'nin yalancı negatif sonuçlar verebilmesine rağmen, laboratuvarlarda rutin olarak kullanılabileceği belirtilmiştir(14).

Murat Mehli ve ark. ${ }^{(16)}$ tarafindan 321 enterik bakteri ile yapılan bir çalışmada ise, GSBL saptamada ÇDS testi ile karşılaştırıldı ğında VITEK 2'nin duyarlılık ve özgüllüğü sırasıyla \%100, \%94.1 olarak saptanmıştır.

Moleküler metodlar referans alınarak 1129 enterik bakteri ile yapılan bir başka çalışmada ise, VITEK-2'nin duyarlılığı \%98.1, özgüllüğüu \%99.7 olarak saptanmıs ve VITEK 2 otomatize sisteminin GSBL saptamada rutin olarak kullanılabileceği sonucuna varılmıştır ${ }^{(17)}$.

E. coli suşlarında GSBL saptanması için çeşitli yöntemlerin karşılaştırıldı ̆̆ı bir çalışmada, çal1şılan 42 suştan 20'si ÇDS testi ile, 15'i VITEK 2 ile GSBL pozitif olarak saptanmıştır. En fazla pozitifliği 40 suşla ChromID ${ }^{\circledR}$ ESBL (bioMérieux, Fransa) yöntemiyle saptamalarına rağmen, ÇDS testinin fenotipik metotlar arasında, E. coli suşlarında GSBL saptanması için en uygun metot olduğunu belirtilmiştir ${ }^{(18)}$.

Çalışmamızda, ÇDS testi ile karşılaştırıldığında VITEK 2'nin duyarlılı̆̆ $\% 93.3$, özgüllüğüu $\% 81.8$, yanlış pozitiflik oranı \%18.1, yanlış negatiflik oranı \%6.6 ve doğruluk oranı \%86.4 olarak saptanmıştır. Ancak ÇDS testinin de güvenilirliğinin azaldığı bazı durumların olduğu unutulmamalıdır. GSBL ile birlikte yüksek düzey AmpC beta laktamaz, MBL (metallo beta laktamaz) ve KPC (K. pneumoniae beta laktamaz) gibi karbapenemazların üretimi, dışaatım mekanizmaları ve geçirgenlik azalması gibi farklı direnç mekanizmalarının birlikte bulunması GSBL varlığını maskeleyebilir. Ayrıca klavulanik asite dirençli olan bakteriler de ÇDS testi ile değerlendirilemez ${ }^{(1,8)}$. Bu verilere göre, VITEK 2 otomatize sistemi ile GSBL saptanmasında yalancı negatif ve yalancı pozitif sonuçlar alınabilmekle birlikte, duyarlılık ve özgüllüğüinün yüksek olduğu görülmektedir. Ancak bunun referans yöntem olmadığı unutulmamalı, uyumsuz sonuçlarda ikinci bir test ile GSBL varlığ $1 /$ yokluğu doğrulanmalıdır.

\section{KAYNAKLAR}

1. European Committee on Antimicrobial Susceptibility Testing (EUCAST). Guideline on detection of resistance mechanisms. EUCAST Document version 1.0, 2013.

2. Clinical and Laboratory Standards Institute. Performance standarts for antimicrobial susceptibility testing. $24^{\text {th }}$ informational supplement. CLSI Document M100-S24, CLSI, Wayne, PA, 2014.

3. European Committee on Antimicrobial Susceptibility Testing (EUCAST). Expert rules in antimicrobial susceptibility testing. EUCAST Document version 2.0, 2011.

4. Clinical and Laboratory Standards Institute. Performance standards for antimicrobial susceptibility testing. $19^{\text {th }}$ informational supplement. CLSI Document M100-S19, CLSI, Wayne, PA, 2009.

5. European Committee on Antimicrobial Susceptibility Testing (EUCAST). Breakpoint tables for interpretation of MICs and zone diameters. EUCAST Document version $1.0,2010$. 
6. Poirel L, Bonnin RA, Nordmann P. Genetic support and diversity of acquired extended-spectrum $\beta$-lactamases in gram-negative rods. Infect Genet Evol 2012; 12:88393. http://dx.doi.org/10.1016/j.meegid .2012.02.008

7. Dağlar D, Öngüt G. Genişlemiş spektrumlu betalaktamazlar (GSBL) ve tanı yöntemleri. Ínönü Üniversitesi Sağlık Bilimleri Dergisi 2012; 1:1-9.

8. Kaçmaz B, Ece G. Genişlemiş spektrumlu betalaktamaz saptanmasında ikinci, üçüncü ve dördüncü kuşak sefalosporinlerin çift disk sinerji testinde kullanılması ve sefoksitin duyarlılığı. ANKEM Derg 2010; 24:61-4.

9. Abbott SL. Klebsiella, Enterobacter, Citrobacter, Serratia, Plesiomonas, and other Enteobacteriaceae. In: Murray PR, Baron EJ, Jorgensen JH, Landry ML, Pfaller MA, eds. Manual of Clinical Microbiology. $9^{\text {th }}$ ed. Washington, D.C: ASM Press, 2007: 710.

10. Bush K, Palzkill T, Jacoby G. B-lactamase classification and amino acid sequences for TEM, SHV and OXA extended-spectrum and inhibitor resistant enzymes. Lahey clinic. [http://www.lahey.org/Studies] Erişim tarihi:15.05.2015

11. Wiegand I, Geiss HK, Mack D, Stürenburg E, Seifert H. Detection of extended-spectrum beta-lactamases among Enterobacteriaceae by use of semiautomated microbiology systems and manual detection procedures. J Clin Microbiol 2007; 45:116774. http://dx.doi.org/10.1128/JCM.01988-06

12. Colodner R. Extended-spectrum beta-lactamases: a challenge for clinical microbiologists and infection control specialists. Am J Infect Control 2005; 33: 104-7.

http://dx.doi.org/10.1016/j.ajic.2004.07.010

13. Robin F, Delmas J, Schweitzer C, Bonnet R. Evaluation of the Vitek-2 extended-spectrum $\beta$-lactamase test against non-duplicate strains of Enterobacteriaceae producing a broad diversity of well-characte-rised $\beta$-lactamases. Clin Microbiol Infect 2008; 14:148-54. http://dx.doi.org/10.1111/j.1469-0691.2007.01893.x

14. Ece G. Comparison of conventional method and automatized vitek system in the detection of extendedspectrum beta-lactamase in Escherichia coli and Klebsiella pneumoniae isolates. Afr J Microbiol Res 2013; 7:4091-95.

15. Gülay Z. Antibiyotiklere direnç mekanizmaları ve çözüm önerileri: beta-laktamlara ve karbapenemlere direnç. Hastane Infeks Derg 2001; 5:210-29.

16. Mehli M, Zer Y, Gayyurhan E. Çeşitli klinik örneklerden izole edilen Enterobacteriaceae suşlarında GSBL oluşturmanın ÇDST ve VITEK 2 yöntemleri ile arastırılması. ANKEM Derg 2007; 21:71-5.

17. Spanu T, Sanguinetti M, Tumbarello $M$, et al. Evaluation of the new VITEK 2 extended-spectrum beta-lactamase (ESBL) test for rapid detection of ESBL production in Enterobacteriaceae isolates. $J$ Clin Microbiol 2006; 44:3257-62. http://dx.doi.org/10.1128/JCM.00433-06

18. Kałużna E, Zalas-Więcek P, Gospodarek E. Comparison of detection methods for extendedspectrum beta-lactamases in Escherichia coli strains. Postepy Hig Med Dosw (online) 2014; 68:808-13. http://dx.doi.org/10.5604/17322693.1108873 